\title{
Understanding the Attitudes of Teenagers towards Reuse and Recycle in Paper Usage
}

\author{
Raja Ahmad Iskandar Raja Yaacob, Abdul Mutalib Embong, Azelin Mohamed Noor, Puteri Zarina \\ Megat Khalid, and Mahfuzah Rafek
}

\begin{abstract}
Pollution is one major problem that has never been completely solved up until now. Though it has been discussed and debated for over decades, these continuous acts are becoming more harmful to human beings as well as the environment. As the seriousness of the matter started to capture world's attention, solution such as recycling has been put forward. Imperative as it is, the responsibility falls on human attitudes to apply recycling in daily life. Among the matter discussed is paper usage which is indisputably very prominent in human life particularly teenagers. With 408 teenagers as respondents, the objectives of this paper are to identify the perceptions' of teenagers in reusing as well as recycling papers in their life. The findings indicate that even though they were aware with the need of reusing and recycling, they did not practise it in life.
\end{abstract}

Index Terms-Pollution, recycle, reuse, teenagers, environment.

\section{INTRODUCTION}

The current vast development in the aspects of social and economy of Malaysia is parallel with the never-dying issue of waste management. Though depicted as trivial, it has yet to be fully implemented and thus far from being successful. Due to the increase in population, economic, inadequate enforcement of waste legislation, infrastructure, and -most crucially- public attitudes especially teenagers, solid waste management has become one of the most discussed issues in Malaysia [1].

Malaysia is daunted by the deteriorating quality of the environment day by day. According to Solid Waste Management and Public Cleaning Corporation Recycling and Public Awareness Division(PPSPPA), 99 per cent of the 17,000 respondents interviewed during the survey admitted that they were aware of the reuse, reduce and recycle (3R) program, but only 68.8 per cent were committed in putting it into practice [2]. This therefore proves that though most Malaysian is aware of the issues yet somehow choose to ignore it.

It is without a doubt that the solid waste management of Malaysian can be considered as critical at present. Regardless the campaigns and exhibition as well as advertisement

Manuscript recieved May 10, 2014; revised July 16, 2014.

Raja Ahmad Iskandar Raja Yaacob, Abdul Mutalib Embong, and Azilin Mohd Noor are with the Universiti Teknologi Petronas (e-mail:\{Iskandar_yaacob, mutalib_embong, azelin_noor\}@petronas.com.my).

MahfuzahRafek is with the Universiti Teknologi Mara (e-mail:mahfu001@ perak.uitm.edu.my).

PuteriZarinaMegat Khalid is with the Unikl Mimet (e-mail: puterizarina@mimet.unikl.edu.my). prepared for the purpose to inculcate the awareness, many still neglect the needs to practice 3R(Reduce, Reuse, Recycle). Reflected by the number of garbage thrown by Malaysian per day, the challenge that the government has to face will never be insignificant. Malaysian-as the matter of fact- on the average throws away $1.64 \mathrm{~kg}$ of waste per day and this amount is considered as unusual as compared to others in the world where the blame normally being parked on the responsibility of the teenagers who are expected to practice $3 \mathrm{R}$ in their daily life [3]. As teenagers usually use lots of paper in life when it comes to studies, there are doubts whether they practice reuse and recycle paper during their study time. This study thus aims to investigate teenagers' practices of reuse and recycle paper in their daily life.

\section{LITERATURE REVIEW}

Numerous mediums are integrated with the intension to cultivate the awareness of solid waste management. Mediums like posters, newspaper, television, radio etc are the platforms to broaden the information on $3 \mathrm{R}$. Though the allocation given to instill the awareness among public has reached million of Ringgit Malaysia, the outcome has also yet to be seen.

3Rs program is mainly developed to reduce the nation's generation of solid waste by REDUCE, REUSE, and RECYCLE. The main objective this particular programwhich is in line with the National Recycling Target- is to have a total of $22 \%$ of the solid waste recycled by the year of 2020 [2]. Nevertheless, current rate is perceived as very low with $11 \%$ as compared to $57 \%$ in Singapore and $66 \%$ in Germany. In most of the developing country in the world, the local governments have the authority and responsibility for the collection and disposal of the solid waste, yet still the management system remain inadequate and expensive [4].

With the current alarming situation, the solid waste management services need to be improved as to modernize the system [5]. Furthermore, a holistic and integrated effort must be made to minimize the quantity of solid waste generated, and this requires the cooperation and full participation of those who generate the waste, which includes the general public [4]. Furthermore, the teenagers' role in managing the solid waste particularly in the use of paper is also a prominent issue.

It is a fact that recycling and reusing behaviour has become a routine or habit with recognised awareness of ecology and recycling [6]. This includes high involvement and participation of the teenagers themselves in ensuring the recycling process to be as effective and continuous as it is supposed to be. However, without a high level of involvement, the earth is-and will always be- threatened by 
each paper that goes un-recycled. In Malaysia, the paper recovery rates hover only around $60 \%$ which indicates that if 10 sets of newspaper were produced, only 6 sets were managed to be recycled [9].

Despite becoming one of the largest energy consumers in the world, pulp and paper industry is also a major producer of greenhouse gases and pollutions [7]. Initiatives like reusing the paper as well as double-sided printing of paper are practised among teenagers especially students. The idea was executed by a group of students who strive to make a difference in University of Toronto who generally initiates the Double-Sided Printing Initiative or UTBEAT's paper conservation project. As of October 2009, the Double-Sided Printing Initiative has succeeded in getting over 70 instructors to request or require double-sided assignments, while UTBEAT succeeded in persuading one of the largest courses on campus to adopt a few conservation strategies that snowballed into 10,000 sheets a year saved [8]. This definitely is a start to save the world from the gruesome effect like landslide-due to trees cutting-save money as well as avoid open burning for paper disposal [9].

Actions and efficient incentives are structured to serve as motivation and to encourage people to recycle and reuse their paper. Changing from textbook to e-book is also one of the ways to reduce the paper usage particularly by students. Recycling assignment paper, reusing papers are steps practiced towards paperless lesson in order to create a more environmental friendly learning condition. It should be noted that today's adoption process does not require much effort. This implies that public, specifically teenagers need to grasp the consequence should the practices are still treated as trivial.

\section{METHODOLOGY}

In this study, a survey was conducted to 408 teenagers from several states in Malaysia. The survey consisted of two sections whereby the first section seeks the personal information such as gender, race, age, occupation, income, residential area and state. The second section is geared towards finding the information on the teenagers' perceptions on recycling and reusing paper. Statements included are based on the teenagers' perceptions for awareness and practices of recycling and reusing paper in while studying. The survey consists of three choices of answers which are 'Yes', 'No' and 'Not Sure'. The Statistical Package for the Social Sciences (SPSS) version 19.0 was used as computer software to analyze the collected data.

\section{FINDINGS}

\section{A. Teenagers' Perception on Reusing Paper}

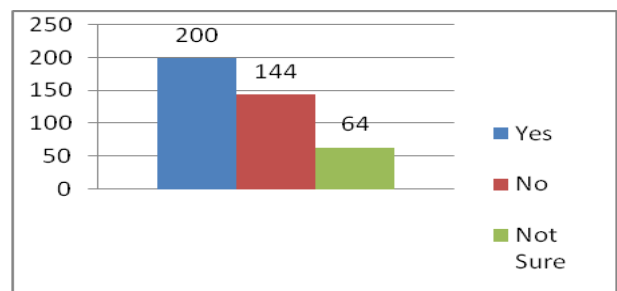

Fig. 1. I reuse my senior's notes and text books rather than buying a new one.
Looking at the graph it can be seen that out of 408 students surveyed, 200 students (49.02\%)reuse their seniors ' notes and text books rather than buying new ones. On the other hand, 144 students (corresponding to $35.29 \%$ ) replied that they did not reuse their seniors' notes and text books and less than $20 \%$ of the students didn't voice themselves about the statement I reuse my senior's notes and text books rather than buying a new one.

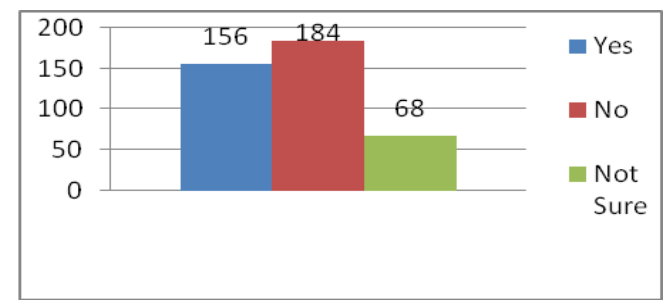

Fig. 2. I always use old papers that have not been used before to write/print rather than new papers.

The graph shows that, the highest percentage of students surveyed (45.1\%) disagreed with the statement I always use old papers that has not been used before to write/print rather than new papers. However, a comparable number of 128 students (which is 38.23) were in agreement with the above statement and 48 students or $11.77 \%$ were neutral whether or not they always use old papers that have not been used before to write/print rather than new papers.

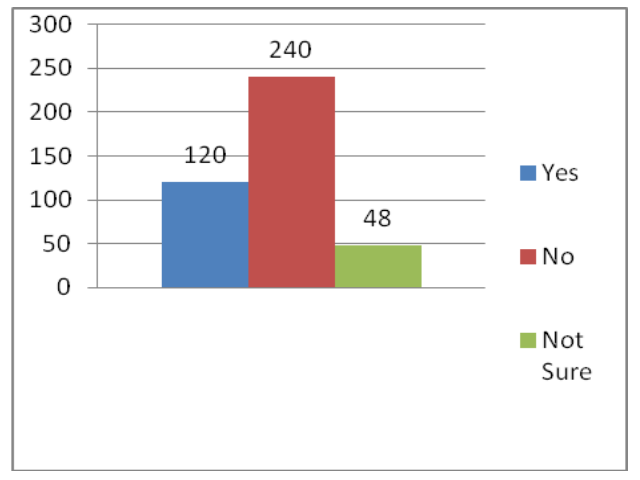

Fig. 3. I have joined book expo to buy/sell used books

The graph indicates that an overwhelming number of 240 students surveyed corresponding to $58.82 \%$ disagreed when asked if they joined book expo to buy/sell used books. However, 120 students agreed that they joined book expo to buy/sell used books. Last but not least, 48 students (which is $11.76 \%$ ) were unsure about the mentioned statement.

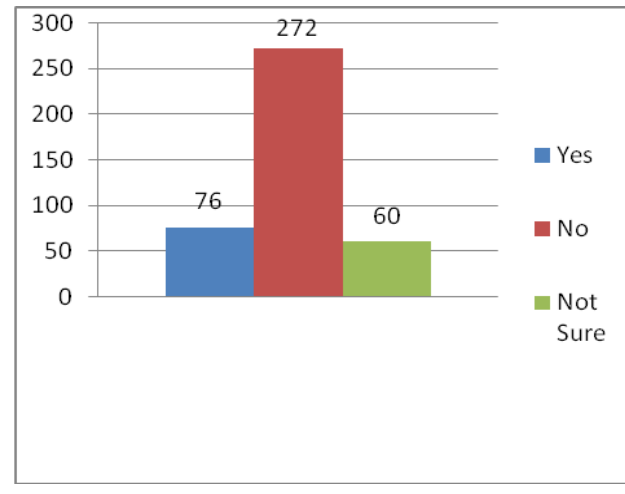

Fig. 4. I always use papers that still left with blanks. 
Observing the graph, an overwhelming majority of the students surveyed (272 students or $66.67 \%$ ) answered no to the statement I always use papers that still left with blanks. However, less than one third of the students surveyed (18.63\%) said that they always use papers that still left with blanks and another 60 students $(14.70 \%)$ were unsure.

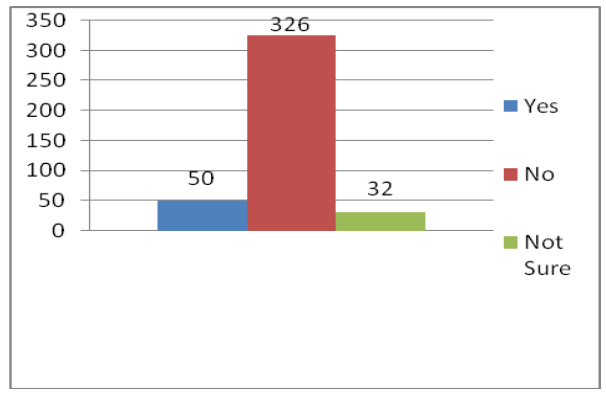

Fig. 5. I throw away text books or notes after use it.

From the graph, it can be seen that the vast majority of the students surveyed (326 students or $79.9 \%$ ) were not in agreement when asked if they throw their text books or notes after using them. In contrast, a small minority of the students surveyed(12.25\%) said that they throw away text books or notes after using them. Meanwhile, another 32 students (which is $14.70 \%$ ) were not sure.

\section{B. Teenagers' Perception on Recycling Paper}

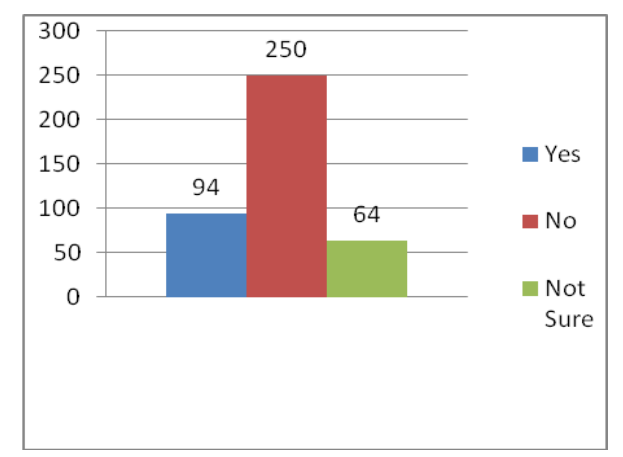

Fig. 6. I always send used papers to the recycling centre

The graph shows that a great proportion of students' surveyed (250 students corresponding to $61.27 \%$ ) answered 'no' when asked if they always send used papers to the recycling centre. However, 94 students were in agreement that they always send used papers to the recycling centre. Last but not least, 64 students (which is $15.69 \%$ ) were not sure about the statement.

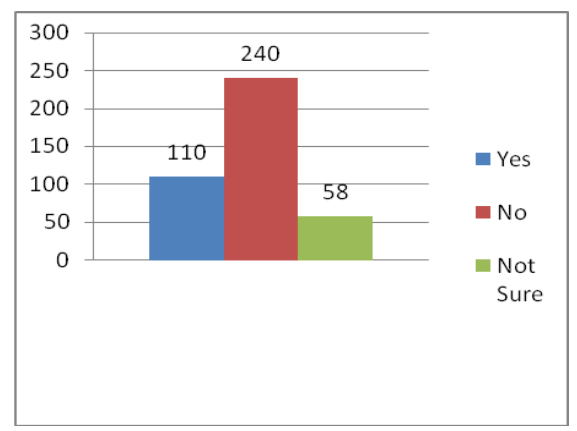

Fig. 7. I join recycling program organized by universities and any related parties.
According to the graph, the highest percentage of students surveyed $(58.82 \%)$ disagreed with the statement $I$ join recycling program organized by universities and any related parties. However, 110 students (which is 26.96\%) were in agreement with the above statement and 58 students or $14.22 \%$ were neutral when asked if they join recycling program organized by universities and any related parties.

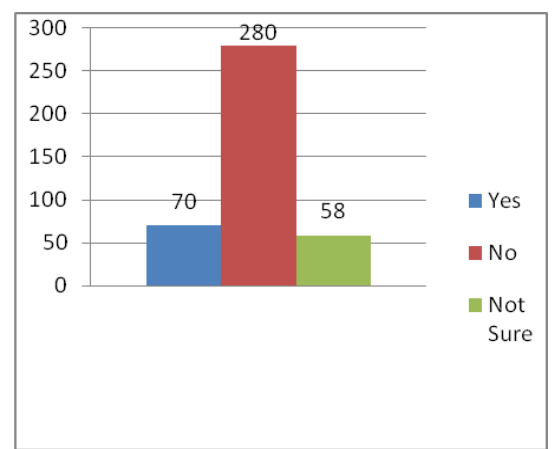

Fig. 8. I think the place for recycling material collection in the campus is readily available.

According to the graph, an overwhelming majority of the students surveyed (280 students or $68.63 \%$ ) denied the availability of place for recycling material collection in the campus. However, less than one third of the students surveyed $(17.16 \%)$ said that places for recycling material collection in the campus are readily available while another 58 students $(14.21 \%)$ did not.

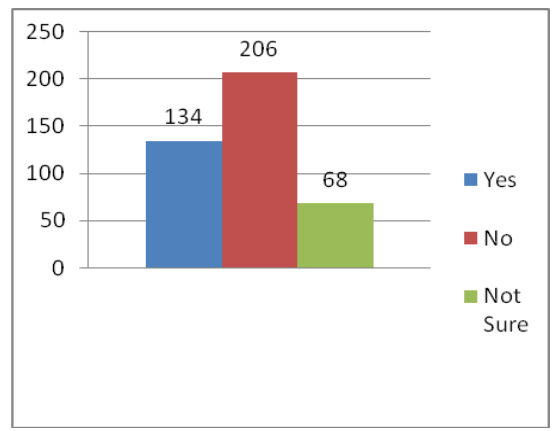

Fig. 9. I always recycle my text book after use it.

The graph indicates that, the highest percentage of students surveyed $(50.49 \%)$ disagreed when asked if they recycle their text book after using them.However, 134 students (which is $32.84 \%$ ) were in agreement with the above statement and 68 students or $11.77 \%$ were neutral whether or not they always recycled their text book after using it.

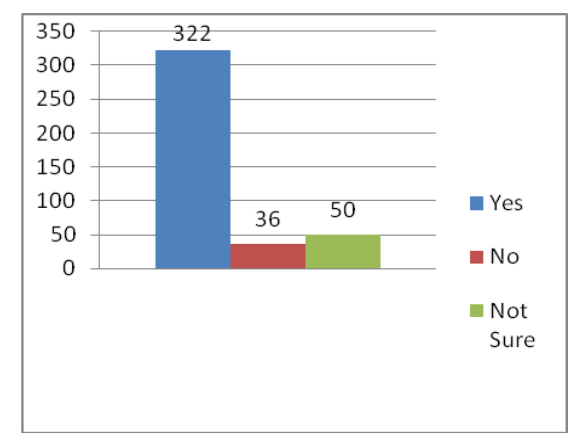

Fig. 10. I realise that wasting paper can cause greenhouse effect. 
The graph shows that a majority of 322 students surveyed (which is $78.92 \%$ ) said that they realise that wasting paper can cause greenhouse effect. Whereas, 50 students surveyed were neutral to the statement I realise that wasting paper can cause greenhouse effect. Finally, less than $10 \%$ of the students surveyed(precisely 36 students) did not concur with the statement above mentioned.

\section{DISCUSSION}

The findings above have shown us a rather disturbing picture of how 'involved' Malaysian teenagers are in the practice of paper recycling and reusing. Their indifference towards the actual practice of recycling and reusing materials is a stark contrast of their belief in the importance of conservation of earth. A majority of the respondents in the study did not embrace the right attitude towards conserving used items in their daily life as students.

From the analysis conducted, it was found that the teenagers generally did not consume reused paper-based materials in their daily life. $49 \%$ of the respondents admitted to reusing their seniors' notes or textbooks. This may due to their desire to save money for the purchase of new books. However $45 \%$ did not use recycled papers for writing or printing. 59\% of the population was also not used to joining book expositions (expo) to either buy or sell their used books. A huge number of the respondents (67\%) also did not use back the books or materials with some blanks left in them. The reason may be due to their refusal to mix subject matters in the same single book. A whopping $80 \%$ of the respondents admitted that they did not dispose of their used books or other materials after using them. This practice may be attributed to their desire to keep them for future references.

On the recycling paper practice, the students too fared equally distressingly. A majority of them admitted that it was not their habit to recycle paper-based materials. $61 \%$ of them did not send recycled papers to the recycling centre. 59\% did not join any recycling programs organized by the university. $69 \%$ were not even aware of the availability of the recycling facilities in the campus. 50\% admitted to not recycling books after using them. This habit may be attributed to their practice of keeping the materials for future use. On the contrary, when asked whether they were aware of the possible greenhouse effects as a consequence of paper wastage, $79 \%$ admitted they were.

The findings supported the study reported which stated that only $68.8 \%$ from 17,000 respondents practised recycling [1]. However, the findings of this study also do not support a study that recycling and reusing behaviour has become a routine or habit with recognised awareness of ecology and recycling [6]. This is because the respondents' attitude in our study did not echo the attitude of the respondents in their research. In addition, with the indifferent attitude shown by the respondents in this study, the suggestion to improve the solid waste management services put forth by Badgie et al. (2011) will not be an easy feat.

The cause of this indifferent attitude cannot be directly attributed to their ignorance as the result of their perception reveals otherwise. Despite understanding the effects of their lackadaisical attitude towards conservation efforts, these respondents continued with their destructive habits. It is thus disheartening as these students are our hopes for the management of the world resources in the future. More measures and initiatives need to be taken up by the relevant authorities to raise the awareness of inculcating the practice of reusing and recycling amongst the young generations.

\section{CONCLUSION}

With the still-worrisome rate of recycling and reusing of paper among teenagers, Malaysian especially the government needs to start finding the best methods to inculcate the awareness of this issue thus, aiding in saving the environment. The impact that it brings to the environment especially in the long run should not be underestimated. With millions of tree being cut down yearly just to satisfy the need of papers for the sake of studying should be viewed from a different perspective now.

Paperless assignment is not an alien issue anymore with the current technology of internet and e-book that can be downloaded anywhere. Thus, while waiting for people to finally change their perceptions and attitudes towards wise-consuming of paper, it is best for the government, stakeholder and even the teenagers themselves start practicing recycle and reusing paper. Better yet, it is highly advisable for them to strive for online discussion, assignment as well as online references notes and books.

\section{REFERENCES}

[1] D. Badgie, M. A. A. Samah, L. A. anaf, and A. Muda, "Assessment of municipal solid waste composition in Malaysia: management, practice and challenge," Pol. J. Environ. Stud, vol. 21, no. 3, pp. 539-547, 2011.

[2] Recycle Rate still Low in Malaysia. (January 1, 2013). Borneo Post online. [Online]. Available: http://www.theborneopost.com/2013/01/01/recycling-rate-in-malaysia -still-low/

[3] Ahmad Suhaili Idrus. (2013). Why isn't Malaysia Recycling? The Malaysian Reserve. [Online]. Available: http://www.asiageospatialforum.org/2013/Greater_bio.htm

[4] Regional workshop on Municipal Solid waste Management World Health Organization Western Pacific Region -Regional Centre for the Promotion of Environmental Planning and Applied Studies (PEPAS) report (1990), Kuala Lumpur, Malaysia, 1990.

[5] D. Badgie, "Solid waste management system in the Kanifing Municipal Council (KMC)," The Gambia, MSc. thesis, Universiti Putra Malaysia (UPM), 2011.

[6] G. D. Meneses and A. B. Palacio, "Different kinds of consumer response to the reward recycling technique: similarities at the desired routine level," Asia Pacific Journal of Marketing and Logistics, vol. 18, iss. 1, pp. 43-60, 2006

[7] Environment Canada. (2007), Canada's 2007 Greenhouse Gas Inventory. $2009 . \quad$ [Online]. Available: http://www.ec.gc.ca/default.asp?Lang=En\&n=FD9B0E51-1

[8] Paper Cuts for Students. (2014) University of Toronto website, [Online]. Available: http://www.utoronto.com/ on 5 February 2014.

[9] Secret of Recycling (2007). Malaysian Newsprint Industries. [Online]. Available: http://www.newsprint.com.my/.

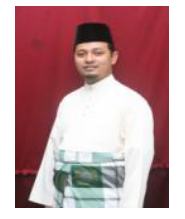

Raja Ahmad Iskandar Raja Yaacob is a senior lecturer at Universiti Teknologi Petronas. He is teaching ethnic relation, Malaysian studies and politics. He obtain his $\mathrm{PhD}$ in knowledge management from Manchester University, UK.

Raja Ahmad Iskandar is with the Department of Management and Humanities, Universiti Teknologi petronas, Bandar Seri Iskandar, 31750, Tronoh, Perak, Malaysia. 


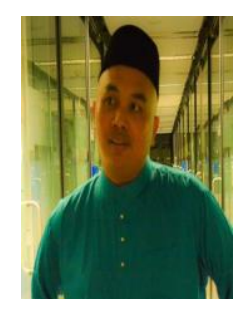

Abdul Mutalib Embong is a lecturer at Universiti Teknologi Petronas. He is teaching technical writing currently, he is doing his $\mathrm{PhD}$ in british discourse analysis at the same university, focusing on colonial newspapers.

Abd Mutalib Embong is with the Department of Management and Humanities, Universiti Teknologi Petronas, Bandar Seri Iskandar, 31750, Tronoh, Perak, Malaysia.

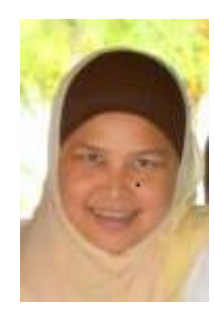

Azilin Mohd Noor is currently a lecturer at Universit Teknologi Petronas. She is teaching professional communication skills. She got her first degree in mass communication and master's degree in TESL from Universiti Teknologi Mara. Her area of study is Adult learners.

Azelin M. Noor is with the Department of Management and Humanities, Universiti Teknologi Petronas, Bandar Seri Iskandar, 31750, Tronoh, Perak, Malaysia.

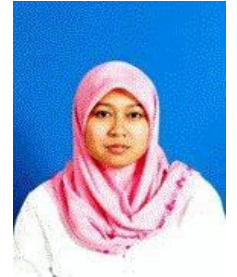

Mahfuzah Rafek is a lecturer at Universiti Teknologi Mara. She graduated from Universiti Teknologi Malaysia (UTM) with both bacheor of science with education (TESL) and master of education (TESL). Her area of interest is educational psychology and second language acquisition.

Mahfuzah Rafekis a lecturer at Academy of Language Studies, Universiti Teknologi Mara, Seri Iskandar 31750, Tronoh, Perak, Malaysia.

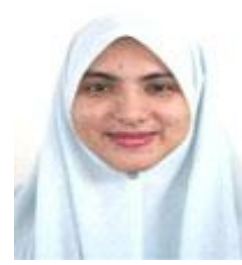

Puteri Zarina Megat Khalid works at Unikl Mimet. She obtained her $\mathrm{PhD}$ from Belfast Queens' Unievrsity and her masters degree from master of education. Puteri Zarina Megat Khalid is a lecturer at Mimet Unikl, Lumut, Perak, Malaysia.

She got master's degree in TESL feom Universiti Perguruan Sultan Idris, and B.Ed. in TESL from Universiti Putra Malaysia. 